\title{
Correction to: SCOPE: safer care for older persons (in residential) environments-a pilot study to enhance care aide-led quality improvement in nursing homes
}

Malcolm Doupe ${ }^{1 *}$, Thekla Brunkert ${ }^{2,3}$, Adrian Wagg $^{4}$, Liane Ginsburg ${ }^{5}$, Peter Norton ${ }^{6}$, Whitney Berta ${ }^{7}$, Jennifer Knopp-Sihota ${ }^{8}$ and Carole Estabrooks ${ }^{9}$

Correction to: Pilot Feasibility Stud 8, 26 (2022)

https://doi.org/10.1186/s40814-022-00975-8

Following publication of the original article [1], the authors reported an error in Fig. 2. The correct figure is given below.

The original article [1] has been updated.

\begin{abstract}
Author details
${ }^{1}$ Max Rady College of Medicine, Rady Faculty of Health Sciences, University of Manitoba, Winnipeg, MB, Canada. ${ }^{2}$ University Department of Geriatric Medicine FELIX PLATTER, Basel, Switzerland. ${ }^{3}$ Nursing Science (INS), Department Public Health (DPH), Faculty of Medicine, University of Basel, Basel, Switzerland. ${ }^{4}$ Department of Medicine, Faculty of Medicine and Dentistry, University of Alberta, Edmonton, Alberta, Canada. ${ }^{5}$ School of Health Policy \& Management, York University, Toronto, Canada. ${ }^{6}$ Department of Family Medicine, University of Calgary, Calgary, Alberta, Canada. Institute of Health Policy, Management \& Evaluation, University of Toronto, Toronto, Canada. ${ }^{8}$ Faculty of Health Disciplines, Athabasca University, Edmonton, Alberta, Canada. ${ }^{9} \mathrm{Fac}-$ ulty of Nursing, University of Alberta, Edmonton, Alberta, Canada.
\end{abstract}

Published online: 01 March 2022

\section{Reference}

1. Doupe M, Brunkert T, Wagg A, et al. SCOPE: safer care for older persons (in residential) environments - a pilot study to enhance care aide-led quality improvement in nursing homes. Pilot Feasibility Stud. 2022;8:26. https:// doi.org/10.1186/s40814-022-00975-8.

The original article can be found online at https://doi.org/10.1186/s40814022-00975-8.

*Correspondence: MalcolmBray.Doupe@umanitoba.ca

${ }^{1}$ Max Rady College of Medicine, Rady Faculty of Health Sciences, University of Manitoba, Winnipeg, MB, Canada

Full list of author information is available at the end of the article

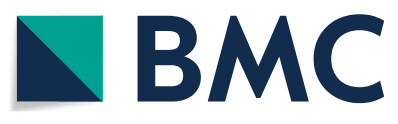

Ther(s) 2022. Open Access This article is licensed under a Creative Commons Attribution 4.0 International License, which permits use, sharing, adaptation, distribution and reproduction in any medium or format, as long as you give appropriate credit to the original author(s) and the source, provide a link to the Creative Commons licence, and indicate if changes were made. The images or other third party material in this article are included in the article's Creative Commons licence, unless indicated otherwise in a credit line to the material. If material is not included in the article's Creative Commons licence and your intended use is not permitted by statutory regulation or exceeds the permitted use, you will need to obtain permission directly from the copyright holder. To view a copy of this licence, visit http://creativecommons.org/licenses/by/4.0/. The Creative Commons Public Domain Dedication waiver (http://creativeco mmons.org/publicdomain/zero/1.0/) applies to the data made available in this article, unless otherwise stated in a credit line to the data. 


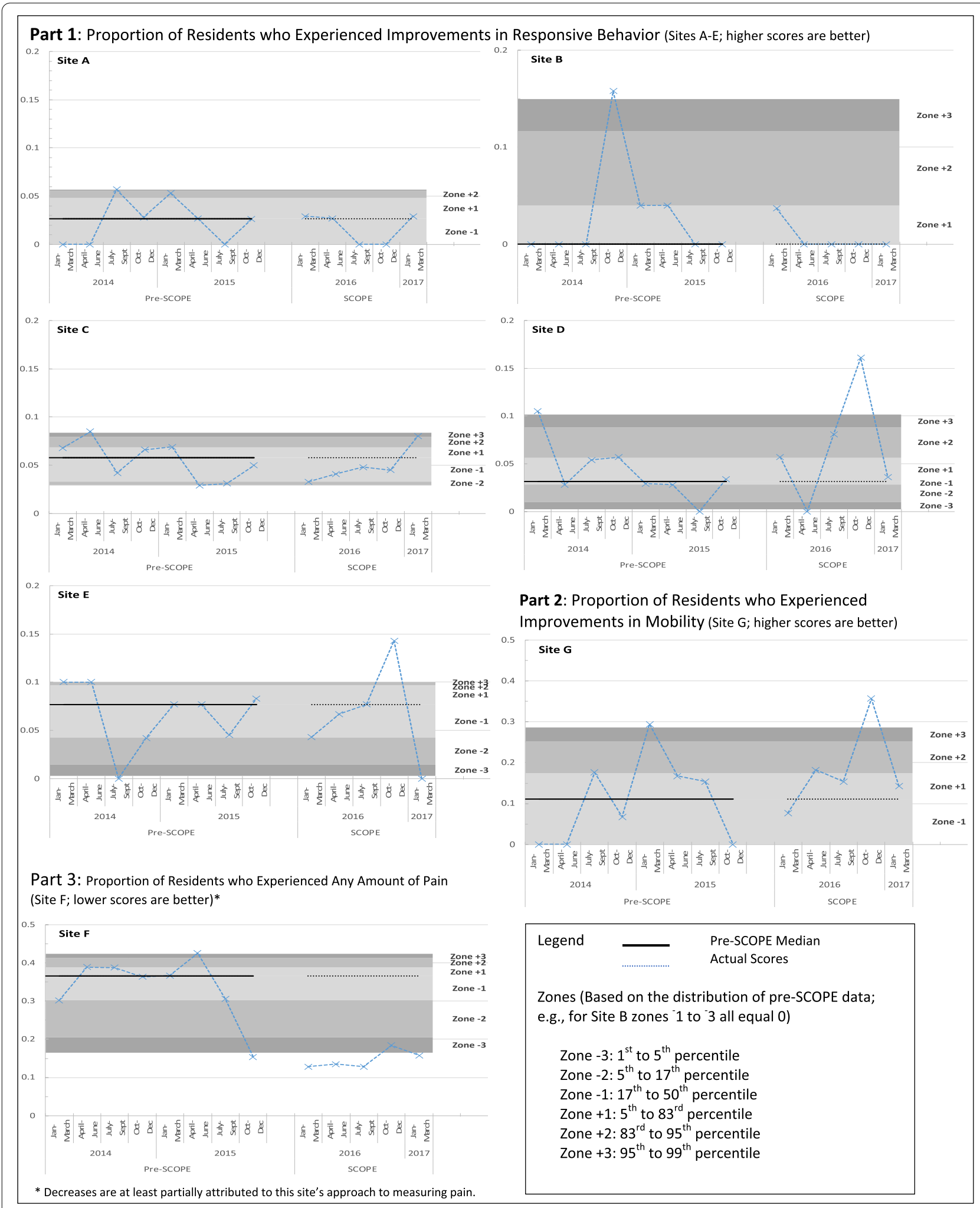

Fig. 2 Unit-level clinical outcomes prior to and during the SCOPE pilot 